\title{
Is there a requirement for advanced airway management for trauma patients in the pre- hospital phase of care?
}

\author{
David J Lockey*, Beth A Healey, Anne E Weaver, Graham Chalk, Gareth E Davies \\ From London Trauma Conference 2013 \\ London, UK. 10-13 December 2013
}

\section{Background}

This study was performed to establish the frequency of pre-hospital airway compromise in trauma patients attended by a UK physician-led pre-hospital service and the role of advanced airway interventions in the treatment of the compromise.

\section{Method}

Over a one year period (April 2012-March 2013) all prehospital trauma patients attended by the doctor-paramedic LAA team who were identified as having airway compromise or an indication for any airway intervention on scene were included in a prospective observational study. The doctor paramedic team recorded any airway compromise on arrival and prior interventions carried out by ambulance service personnel.

\section{Results}

472 patients met the inclusion criteria. Ambulance service personnel attended before the enhanced care team in 469/472 (99.4\%) of cases. 200 patients had no evidence of compromise of which 134 (67\%) had received airway interventions by the ambulance service. 269 (57\%) had airway compromise at the point of arrival of the enhanced care team. Of the 269 with airway compromise, 174 had complete or partial airway obstruction and 145 had gross contamination with blood or vomit. Ninety-eight patients received paramedic advanced airway management interventions (intubation without drugs or supraglottic airway insertion). 48/50 (92\%) supraglottic airway insertions and 29/45 (64\%) intubations were successful. All patients had successful pre-hospital intubation by the enhanced care team before transport to hospital.

Londons Air Ambulance, Royal London Hospital, London E1 1BB, UK

\section{Discussion}

The reported results suggest a requirement for on-scene advanced airway management in a relatively small number of severely injured trauma patients. Standard ambulance service interventions do not appear to adequately treat airway compromise in a small proportion of trauma patients. Intubation without drugs had a high failure rate. These results suggest that the airway management problems reported in the NCEPOD report: Trauma who cares? in 2007 still exist.

Published: 7 July 2014

\section{Reference}

1. NCEPOD Trauma: Who Cares? A report of the National Confidential Enquiry into Patient Outcome and Death 2007.

doi:10.1186/1757-7241-22-S1-P8

Cite this article as: Lockey et al.: Is there a requirement for advanced airway management for trauma patients in the pre-hospital phase of care? Scandinavian Journal of Trauma, Resuscitation and Emergency Medicine 2014 22(Suppl 1):P8.

Submit your next manuscript to BioMed Central and take full advantage of:

- Convenient online submission

- Thorough peer review

- No space constraints or color figure charges

- Immediate publication on acceptance

- Inclusion in PubMed, CAS, Scopus and Google Scholar

- Research which is freely available for redistribution 